\title{
SEISMIC PHENOMENA IN THE LIGHT OF HIGH-RATE GPS PRECISE POINT POSITIONING RESULTS
}

\author{
Iwona KUDLACIK ${ }^{1)}$, Jan KAPLON ${ }^{1)}$, Jaroslaw BOSY ${ }^{1)}$ and Grzegorz Lizurek ${ }^{2)}$ \\ 1) Wroclaw University of Environmental and Life Sciences, Institute of Geodesy and Geoinformatics, Grunwaldzka 53, \\ 50-357 Wroclaw, Poland \\ ${ }^{2)}$ Polish Academy of Sciences, Institute of Geophysics, Księcia Janusza 64, 01-452 Warszawa, Poland \\ *Corresponding author's e-mail: iwona.kudlacik@upwr.edu.pl
}

\section{ARTICLE INFO}

Article history:

Received 24 November 2018

Accepted 16 January 2019

Available online 7 March 2019

\section{Keywords}

High-rate GNSS

PPP

GNSS-seismology

\begin{abstract}
The motion of GPS permanent stations during three earthquakes has been investigated with the use of Precise Point Positioning (PPP) technique and the data obtained by seismic sensors. The study examines the ability of high-rate GPS observations to reflect the ground motion retrieved by the strong motion instruments (SM), considered to be more reliable and precise. The goal of this article is to show the sensitivity of GPS PPP kinematic high-rate positioning with position domain filtering using the band-pass Butterworth filter on small samples of position time series. The kinematic PPP approach in RTKLib software was used, supported by the CODE precise orbit and clock products to estimate positions from 5-hour long GPS phase datasets. Obtained position time series were reduced to 5-minute samples covering the time of co-seismic motion. The application of Butterworth band-pass filtering of GPS and SM time series increased the agreement between them up to $72 \%$ in terms of correlation, resulting in correlations within the range 0.34 to 0.99 . The comparison of peak ground displacements (PGD) revealed that for Italian events, GPS-SM absolute value of the average difference is $6 \mathrm{~mm}$ with GPS-SM distances within the range of 0.05 to $2.14 \mathrm{~km}$. In all analysed earthquakes, the agreement between GPSgrams and seismograms in terms of the first P-arrival polarity was checked and it was found that it is consistent in all cases. This confirms the GNSS technique capability for determining fault plane solution for earthquakes with magnitudes over 6.
\end{abstract}

\section{INTRODUCTION}

Among many geophysical processes in the Earth, it is worthwhile distinguishing earthquakes, which happen every day across the world and the strongest of them may cause severe damages. Each earthquake produces seismic waves that travel around the world. Depending on the strength of event, the ground movement may be felt locally or regionally or might be only recorded by sensitive instruments. The earthquake's source may be natural, like crustal deformation or induced, for example, by mining activity. Geophysical techniques, sometimes in connection with geodetic techniques (e.g. levelling, InSAR and GNSS), are used to investigate the potential causes and results of geodynamic events, which may provide additional information about ground displacements (e.g. Massonnet et al., 1993; Elliott et al., 2011; Houlié et al., 2014; Dreger et al., 2015; Kelevitz et al., 2017). The GNSS observations are often used to observe static co-seismic threedimensional displacements but they can also be used to estimate dynamic displacements. For large-scale earthquakes, the GNSS receivers may even replace strong-motion instruments (eg. Hung and Rau, 2013; Hung et al., 2017). On the other hand, for small events, it is efficient to combine the GNSS and seismic observations, since these two methods are complementary.

The topic of GNSS-seismology was described by Bock et al. (2000) and Larson et al. (2003), then further developed by Genrich and Bock (2006), Larson (2009), Smalley (2009), Avallone et al. (2011) and Hung and Rau (2013), among others. The recent developments in seismological geodesy are summarized by Bock and Melgar (2016) and Xu et al. (2016). First, GNSS observations leads to position and displacement computation, whereas the strong-motion instruments are registering the velocity or acceleration of the earth's crust during the tremor and the displacements are obtained by single or double integration, which is problematic (eg. Melgar et al., 2013; Wang et al., 2013; Li et al., 2014). The inconsistency between time series appears mainly due to the distance between the location of strong motion instruments and GNSS receivers, there may appear differences in the seismic wave propagation time and the event strength. The other reason is the rotation of the sensor during shaking - so called baseline error described by Boore (2001), Wang et al. (2013) and Melgar et al. (2013). The co-location limit of good 
agreement was set at $4 \mathrm{~km}$ by Emore et al. (2007). Furthermore, Avallone et al. (2011) stated the agreement within $\pm 1 \mathrm{~cm}$ accuracy of the position time series between closely spaced seismic and GNSS observatories. Moreover, strong-motion instruments are more sensitive than GNSS sensors, which on the other hand are not affected by drift, tilt and clipping and provide spatial observations with respect to a global terrestrial reference frame. The weaker sensitivity of GNSS observations makes them unsuitable for far-field response to small and moderate earthquakes (Bock and Melgar, 2016). Nevertheless, there are studies that demonstrate the potential to use GNSS in monitoring small-magnitude earthquakes (e.g. Saunders et al., 2016). The limitation of real-time GPS-only solutions are considered as centimetre level or even better (e.g. Genrich and Bock, 2006; Psimoulis et al., 2015; Michel et al., 2017; Shu et al., 2018; Yu et al., 2018). Most GNSS permanent stations record data with a sampling interval between 1 to 30 seconds, which is not optimal to reflect the earthquake process. Since receivers are able to record data with higher frequency, studies showing the application of high-rate GNSS observations for seismic studies are also popular (e.g. Avallone et al., 2011; Smalley, 2009; Genrich and Bock, 2006). Optimal GNSS observation frequency is usually found using displacement simulations (e.g. Genrich and Bock, 2006; Smalley, 2009) and then tested in the analysis of natural earthquakes (e.g. Smalley, 2009; Avallone et al., 2011). According to Avallone et al. (2011), although $1 \mathrm{~Hz}$ data is enough to detect dynamic deformations, recording frequencies greater than $2.5 \mathrm{~Hz}$ are needed for detailed studies on rupture processes of moderate-magnitude events through GPS dynamic displacements. Nevertheless, according to Smalley (2009), for magnitude 6 earthquakes, $1 \mathrm{~Hz}$ GNSS time series of dynamic displacements at very small epicentral distances are aliased. For larger events and sampling of $5 \mathrm{~Hz}$, this problem may also occur. Therefore, these data should not be used for spectral analyses or inversions for source parameters (Smalley, 2009). Higher sampling may bring additional information in some cases. Authors point out the $10 \mathrm{~Hz}$ recording frequency is a good trade-off between the reasonable amount of daily data and usefulness to seismological study (Avallone et al., 2011). Considering the features of seismic and GNSS observations, Bock and Melgar (2016) propose that it is efficient to co-locate $1-10 \mathrm{~Hz}$ GNSS receivers with 100-200 Hz frequency accelerographs.

Our approach described here presents data processing scenario including the PPP GPS data processing in short 5-hour sessions, de-trending of PPP-based coordinate time series using band-pass filtering instead of using sidereal filtering method, which requires data from the days preceding the earthquake. The goal is to obtain precise co-seismic displacements using 5-hour long high-rate GPS observations without any additional data from previous days. Then there was performed a statistical evaluation of differences between displacement time series obtained by seismic (SM-displacement) and GPS (GPS-displacement) sensors.

\section{COMPARISON OF GPS-DERIVED WITH SEISMOLOGICAL TIME SERIES PROBLEM}

In order to check the correspondence between data derived by seismic sensors (SM data) and GPS instruments (GPS data), the comparison between acceleration, velocity and displacement have to be done. Since strong-motion instruments (SM) record accelerations or velocities and GPS observations usually leads to obtain position, to compare both methods the integration or differentiation needs to be performed. When the comparison is going to be made in the displacement domain, all SM data must be integrated, which might be problematic as the simple integration of the accelerogram may produce unphysical velocity and displacement waveforms (Melgar et al., 2013). Therefore, a comparison of acceleration, velocity and displacement time series was performed in order to check which option has the best agreement. The example comparison is presented in Figure 1 and Figure 2 for the co-located Italian GUMA GPS station and accelerograph. SM data was processed and band-pass filtered by the National Institute of Geophysics and Volcanology on cut-off frequencies of $0.05-70 \mathrm{~Hz}$. To unify both data types in sampling frequency, we decided to process SM data with a high-pass filter of $2 \mathrm{~Hz}$, as the GPS data in this case was filtered in the range of $0.05-2.00 \mathrm{~Hz}$. The result is visible in Figure 2 - the correlation coefficients are slightly higher than in the first case, where SM data was only decimated to $10 \mathrm{~Hz}$ interval. We will discuss the data processing strategy in detail in chapters 4 and 5 . Here, we would like to justify only the research in the displacement domain for which the best correlation was obtained, since double differentiation of GPS solutions causes noise increase, whereas double integration of low-pass filtered strong-motion accelerations does not induce significant biases and trends. Examples presented in Figure 1 and Figure 2 clearly show that the biggest agreement of GPS and SM results represented by the Pearson correlation coefficient (eg. Witz et al., 1990) were obtained not for velocities (middle plots) or accelerations (right plots) but for displacements (left plots). This fact led us to investigate and present the seismic phenomena derived from the GPS PPP method in the displacement domain only.

\section{TEST CASES AND DATA}

In this study three earthquake events were analysed: the Gorkha (Nepal) earthquake with permanent post-seismic displacement, Visso and Norcia (Italy) with short-term co-seismic displacements during the events. Their parameters are listed in Table 1.

All used GNSS stations operate under permanent networks dedicated to seismic events observations, therefore they are equipped with on high-precision 

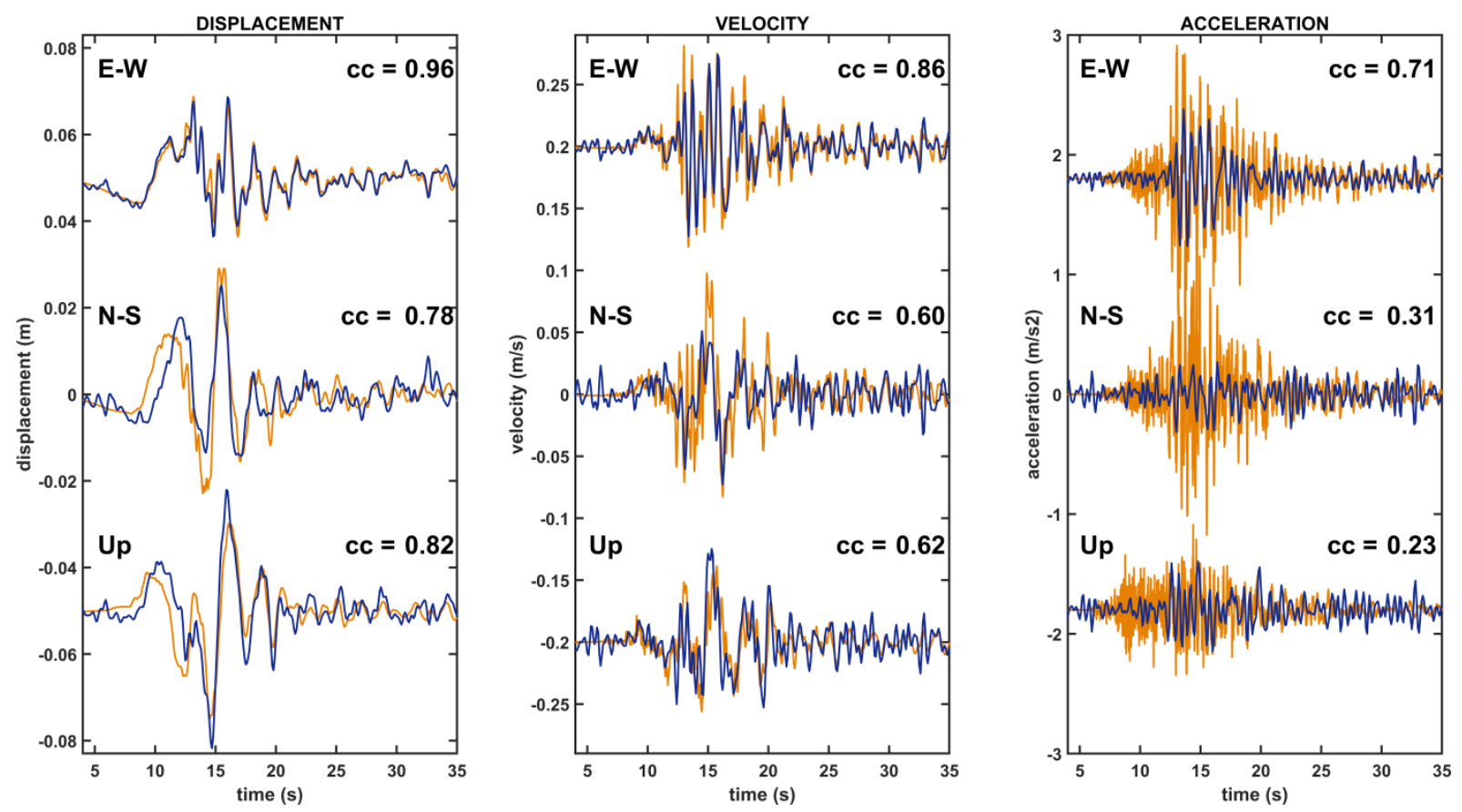

Fig. 1 GPS (black) and SM (grey) displacement, velocity and acceleration time series of Norcia earthquake cropped to analysed time with correlation coefficients of station GUMA. GPS data is band-pass filtered on cut-off frequencies of 0.05-2.00 Hz; seismological data is band-pass filtered by the National Institute of Geophysics and Volcanology (Luzi et al., 2016) on cut-off frequencies of 0.05-70.00 Hz.
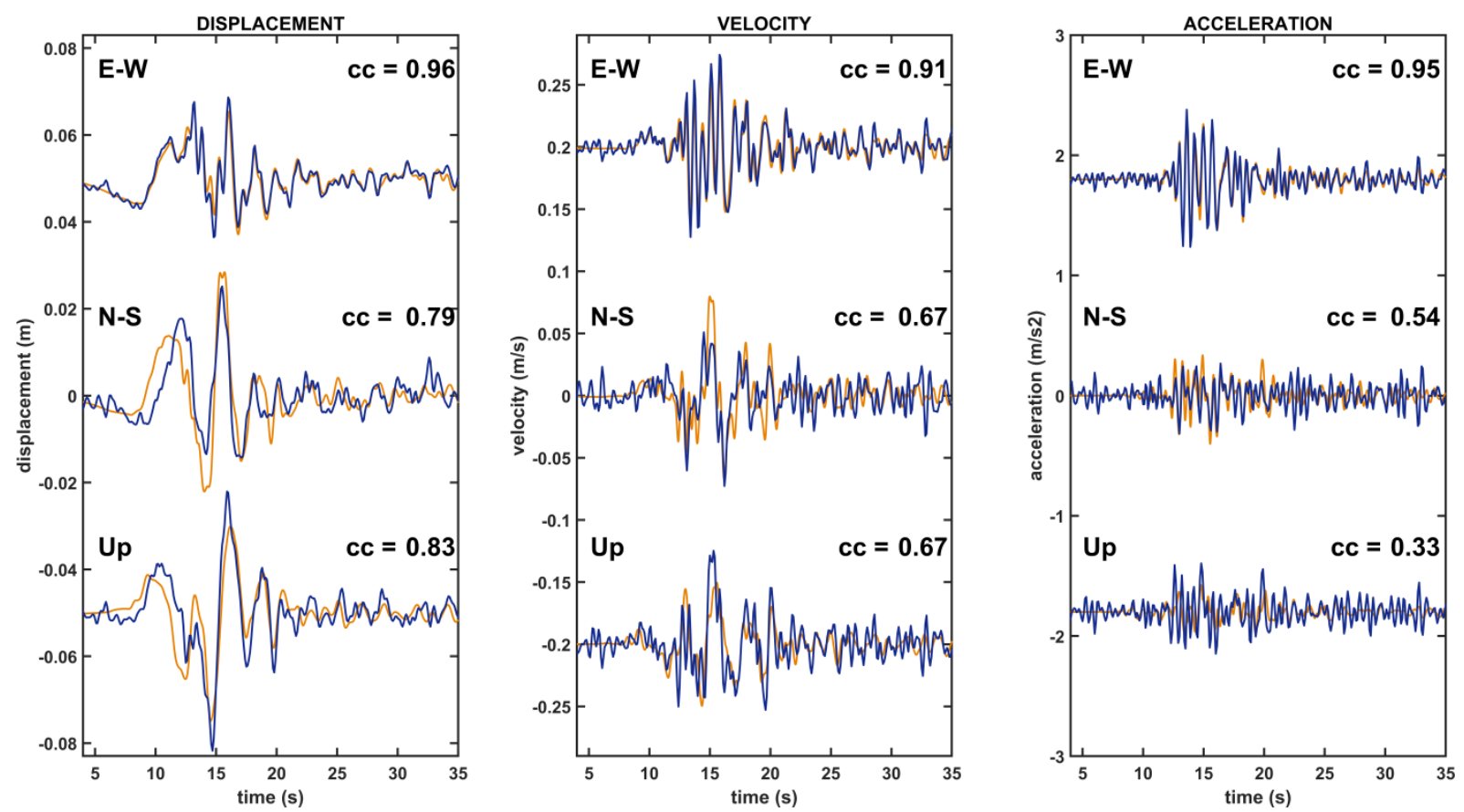

Fig. 2 GPS (black) and SM (grey) displacement, velocity and acceleration time series of Norcia earthquake cropped to analysed time with correlation coefficients of station GUMA. GPS data is band-pass filtered on cut-off frequencies of 0.05-2.00 Hz; seismological data is band-pass filtered by the National Institute of Geophysics and Volcanology (Luzi et al., 2016) on cut-off frequencies of $0.05-70.00 \mathrm{~Hz}$ and then low-pass filtered on a cut-off frequency of $2 \mathrm{~Hz}$. 
Table 1 Parameters of analysed earthquakes. Focal mechanism represented by dip, strike and rake angles of two seismic nodal planes (NP). Based on (USGS National Earthquake Information Center, 2018).

\begin{tabular}{|c|c|c|c|}
\hline NAME & Lamjung / Gorkha & Italy 1 / Visso & Italy 2 / Norcia \\
\hline DATE & $\begin{array}{c}\text { 2015-04-25 06:11:25 } \\
\text { UTC }\end{array}$ & 2016-10-26 19:18:08 UTC & 2016-10-30 06:40:18 UTC \\
\hline $\begin{array}{c}\text { MOMENT } \\
\text { MAGNITUDE (MW) }\end{array}$ & 7.8 & 6.1 & 6.6 \\
\hline LOCALIZATION & $36 \mathrm{~km}$ E of Khudi, Nepal & $3 \mathrm{~km}$ NNW of Visso, Italy & $7 \mathrm{~km}$ north of Norcia, Italy \\
\hline $\begin{array}{c}\text { EPICENTRE } \\
\text { COORDINATES }\end{array}$ & $28.231^{\circ} \mathrm{N} 84.731^{\circ} \mathrm{E}$ & $42.862^{\circ} \mathrm{N} 13.096^{\circ} \mathrm{E}$ & $42.956^{\circ} \mathrm{N} 13.067^{\circ} \mathrm{E}$ \\
\hline DEPTH & $8.2 \mathrm{~km}$ & $8.0 \mathrm{~km}$ & $10.0 \mathrm{~km}$ \\
\hline FOCAL MECHANISM & $\begin{array}{c}\text { thrust } \\
\text { NP1: } 290^{\circ} / 7^{\circ} / 101^{\circ} \\
\text { NP2: } 99^{\circ} / 83^{\circ} / 89^{\circ} \\
\end{array}$ & $\begin{array}{c}\text { normal } \\
\text { NP1: } 333^{\circ} / 40^{\circ} /-92^{\circ} \\
\text { NP2: } 155^{\circ} / 50^{\circ} /-89^{\circ} \\
\end{array}$ & $\begin{array}{c}\text { normal } \\
\text { NP1: } 162^{\circ} / 27^{\circ} /-84^{\circ} \\
\text { NP2: } 335^{\circ} / 63^{\circ} /-93^{\circ}\end{array}$ \\
\hline
\end{tabular}

Table 2 List of analysed co-located GPS-SM stations with their epicentral azimuth, mean epicentral distance and distance between devices.

\begin{tabular}{|c|c|c|c|c|c|}
\hline \multirow[b]{2}{*}{$E Q$} & \multicolumn{2}{|c|}{ SENSOR NAME } & \multirow{2}{*}{$\begin{array}{c}\text { EPICENTRAL } \\
\text { AZIMUTH }\end{array}$} & \multicolumn{2}{|c|}{ DISTANCE [km] } \\
\hline & GPS & ACCELEROGRAPH & & EPICENTRAL & $\begin{array}{l}\text { BETWEEN } \\
\text { DEVICES }\end{array}$ \\
\hline \multirow{2}{*}{ Nepal } & KKN4 & KATN & $124.4^{\circ}$ & 68.0 & 10.5 \\
\hline & NAST & KATN & $131.7^{\circ}$ & 81.7 & 6.3 \\
\hline \multirow{4}{*}{$\begin{array}{l}\text { Italy } 1 \\
\text { (Visso) }\end{array}$} & $\mathrm{ACCU}$ & IT.ACC & $158.9^{\circ}$ & 25.4 & 0.08 \\
\hline & AMAT & IT.AMT & $157.0^{\circ}$ & 33.7 & 0.77 \\
\hline & GUMA & IV.GUMA & $45.6^{\circ}$ & 24.0 & 0.49 \\
\hline & MTER & IV.RM33 & $171.5^{\circ}$ & 44.9 & 0.39 \\
\hline \multirow{6}{*}{$\begin{array}{c}\text { Italy } 2 \\
\text { (Norcia) }\end{array}$} & ACCU & IT.ACC & $144.9^{\circ}$ & 18.5 & 0.08 \\
\hline & AMAT & IT.AMT & $147.0^{\circ}$ & 26.8 & 0.77 \\
\hline & CAPE & IT.CPS & $139.4^{\circ}$ & 81.8 & 0.05 \\
\hline & LTNA & IT.LAT & $186.5^{\circ}$ & 152.4 & 0.62 \\
\hline & ATTE & IV.ATTE & $303.7^{\circ}$ & 74.0 & 0.37 \\
\hline & MUVI & IV.T1216 & $322.7^{\circ}$ & 10.2 & 2.14 \\
\hline
\end{tabular}

geodetic grade receivers and antennas, mostly registering GPS-only signals.

\subsection{GORKHA EARTHQUAKE}

The Gorkha earthquake was a result of thrust faulting because of the overriding Eurasia plate in the north and subducting India plate. The dimension of the thrust plane was about $120 \times 80 \mathrm{~km}$, where the event intensity in the modified Mercalli scale (MMI) ranged from VI-IX, which means severe damages on the earth surface (USGS National Earthquake Information Center, 2018). Seismic data was provided by the Center for Engineering Strong Motion Data (CESMD) by USGS. GPS-only data came from the UNAVCO GPS Archive for Nepal earthquake; these GPS stations belong to the California Institute of Technology in cooperation with the National Seismological Centre (Avouac et al., 2015). The sampling frequency of GPS data was $5 \mathrm{~Hz}$. In the Nepal event, data from eight GPS stations were analysed - two were close to the accelerograph KATN, namely stations KKN4 and NAST, at a distance of $11 \mathrm{~km}$ and $6 \mathrm{~km}$, respectively (Fig. 3). According to Feng et al. (2015) and Galetzka et al. (2015), the earthquake resulted in huge post-seismic horizontal and vertical displacements reaching 1.3 and $1.9 \mathrm{~m}$ recorded by KKN4 GPS station.

\subsection{ITALIAN EARTHQUAKES}

The two chosen Italian events were part of the earthquake sequence from $24^{\text {th }}$ September to $30^{\text {th }}$ October 2016 in the Apennines. Seismic data for these earthquakes were provided by the ITalian ACcelerometric Archive (ITACA) - the accelerographs belong to the Italian Strong Motion Network and Italian National Seismic Network. The sampling frequency of accelerographs was $200 \mathrm{~Hz}$. GPS-only data for the events came from the high-rate GPS data archive database of the 2016 central Italy seismic sequence held by the National Institute of Geophysics and Volcanology (INGV) - the GPS stations belong to the RING Network (Rete Integrata Nazionale GPS), DPC Network (by Dipartimento di Protezione Civile), INGV CaGeoNet GNSS network (The Central Apennines Geodetic Network) and Regione Lazio GNSS network. The sampling frequency was $10 \mathrm{~Hz}$. Dynamic displacements that took place during the $24^{\text {th }}$ September Amatrice earthquake were investigated by Avallone et al. (2016). They analysed GPS displacements with Precise Point Positioning (PPP) and DoubleDifference (DD) approaches using Gipsy/Oasis and TRACK software, respectively. They obtained the accuracies of position time series expressed through RMS within $0.3 \mathrm{~cm}$ and an agreement within $0.5 \mathrm{~cm}$ 


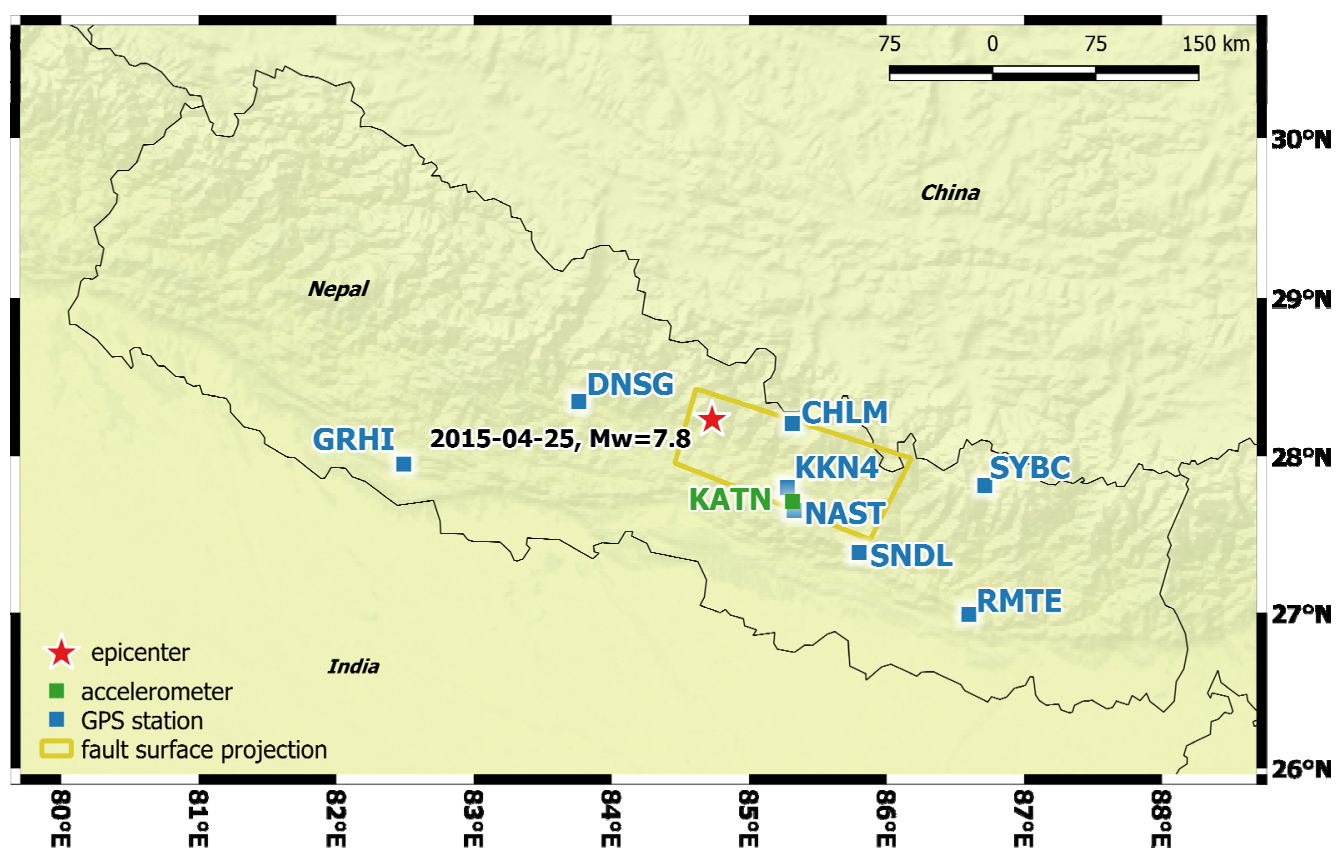

Fig. 3 Map view of the Mw 7.9 Gorkha earthquake - star represents the epicentre, blue squares denote high-rate GPS stations and green square denotes strong-motion station.

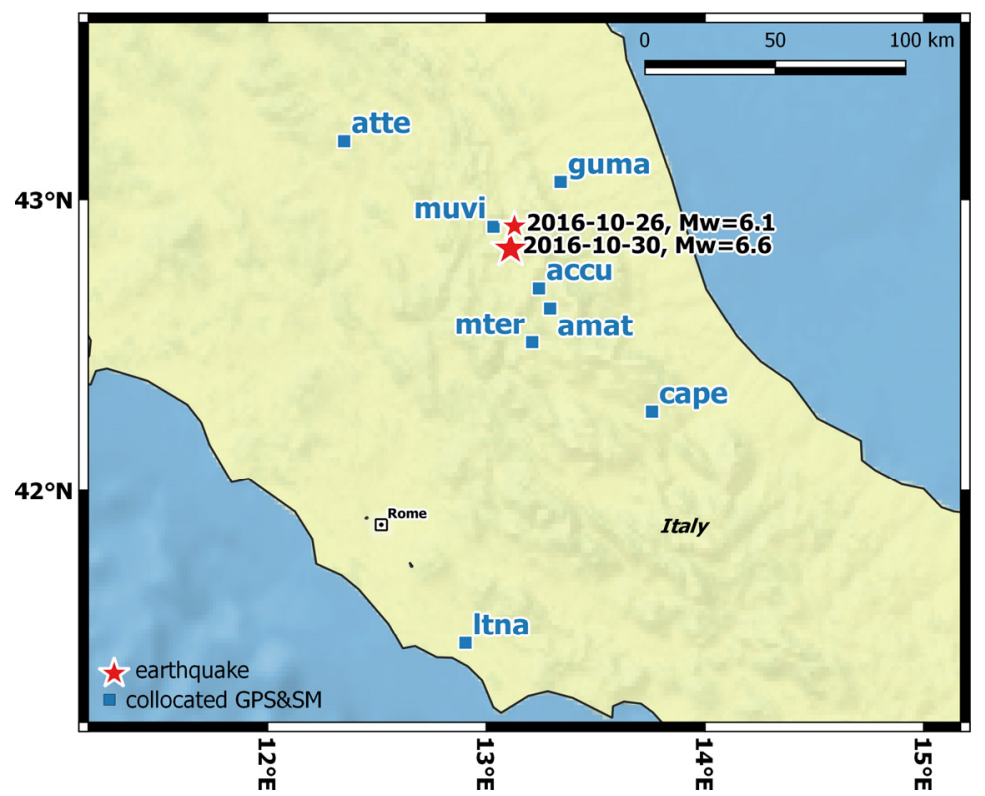

Fig. 4 Map view of Italian earthquakes analysed in this study - red star represents epicentre; blue rectangles denote high-rate GPS stations that are co-located with a strong-motion station within a $2 \mathrm{~km}$ distance.

between results of tested approaches. Analysis of correlations between co-located GPS and seismological data confirmed compatibility between both techniques. The study of the October events was conducted by Fratarcangeli et al. (2018) to present another approach to GPS data processing. The VADASE (Variometric Approach for Displacements Analysis Stand-alone Engine) software was used to estimate the epoch-by epoch displacements equivalent to inter-epoch mean velocities in real-time using the phase observations from the satellites in two consecutive epochs (Colosimo et al., 2011a; Fratarcangeli et al., 2018a). The results from $1 \mathrm{~Hz}$ GPS data were then compared with PPP solution from
Automatic Precise Positioning Server PPP online tools based on GIPSY 6.4 (APP-PPP, http://apps.gdgps.net/) and the maximum discrepancies of $0.7 \mathrm{~cm}$ for the East, $2.6 \mathrm{~cm}$ for the North and $2.3 \mathrm{~cm}$ for the Up component were obtained.

Italian earthquakes were recorded by co-located accelerographs and GPS stations. For the Visso and Norcia earthquakes, 4 (ACCU / IT.ACC, AMAT / IT.AMT, GUMA / IV.GUMA, MTER / IV.RM33) and 6 (aCCU / IT.ACC, AMAT / IT.AMT, CAPE / IT.CPS, LTNA / IT.LAT, ATTE / IV.ATTE, MUVI / IV.T1216) co-located pairs of sensors were analysed, respectively, where the distance between sensors did 

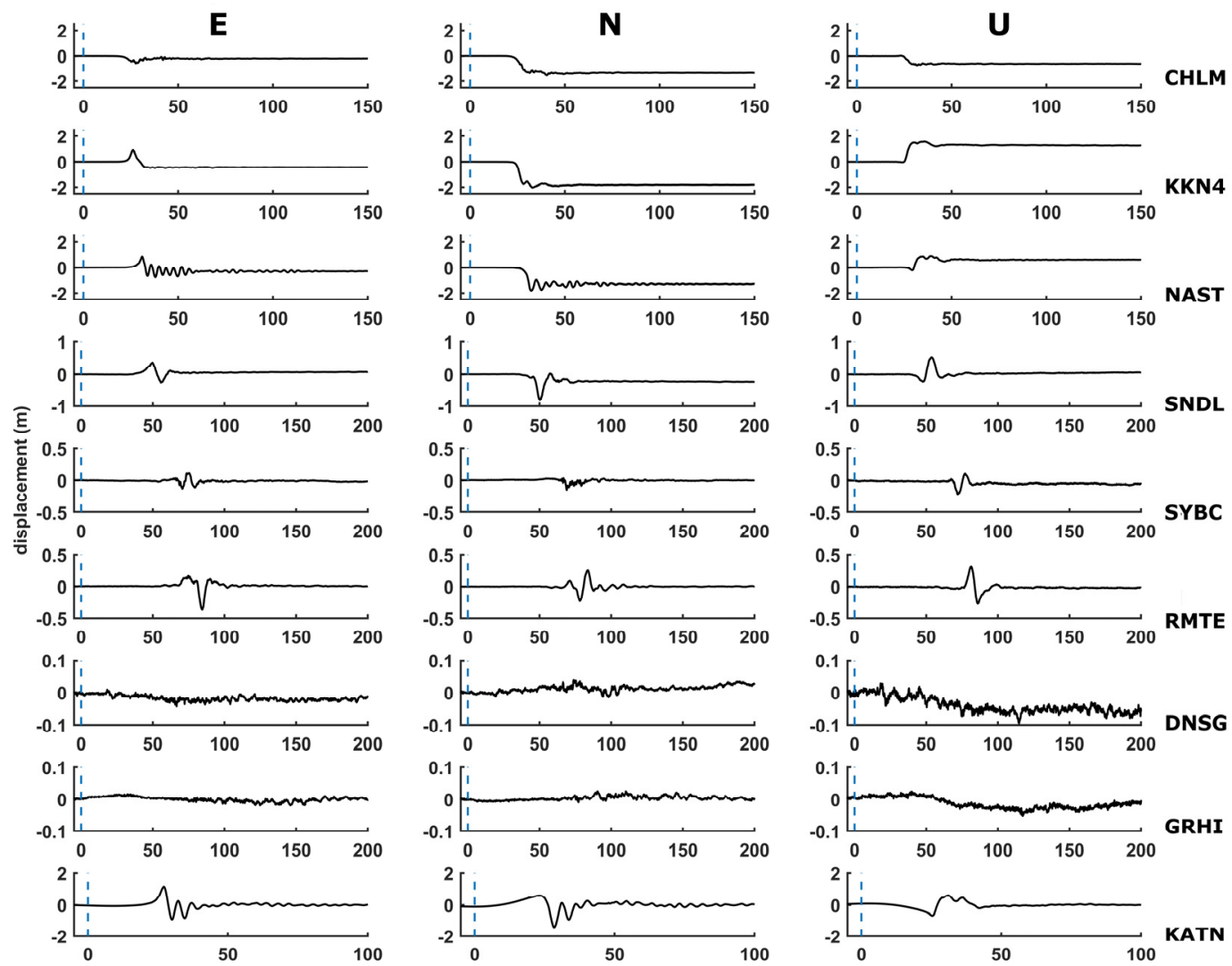

Fig. 5 Gorkha earthquake nonfiltered displacement waveforms at GPS stations and at the strong-motion station (KATN). GPS waveforms might be divided into 3 groups: the first three stations (CHLM, KKN4, NAST), which are located on the fault surface and resulted with permanent displacement; the second three stations (SNDL, SYBC, RMTE), where the shock was clear but not permanent; and the third group (DNSG and GRHI), which are located west of the epicentre in a direction where the waves almost did not propagate. The reference zero time is the time of the main shock.

not exceed 2 kilometres and the epicentral distance of co-located devices was below 100 kilometres (with one exception - ltna / IT.LAT). The locations of the GPS and seismic stations are presented in Figure 4 and the distances between them are listed in Table 2 .

\section{PPP WITH HIGH-RATE GPS DATA}

High-rate GNSS receivers can be an additional source of data for seismic activity research. It is expected that the GNSS data processing products (displacements (eg. Hung et al., 2017), velocities, accelerations (eg. Colosimo et al., 2011b) and phase post-fit residuals (Larocca et al., 2016) and seismic data will allow separately for determining the earthquake event length, the amplitude of displacements and polarisation of seismic waves.

Precise Point Positioning (PPP) is a singlereceiver coordinate determination technique based on multi-satellite to receiver distances measurement that requires the precise correction of various GNSS signal delays in order to obtain the highest precision (Zumberge et al., 1997; Kouba and Héroux, 2001; Hadaś and Bosy, 2014). Nowadays, this technique is evolving into real-time applications (eg. Mervart et al., 2008; Hadaś, 2015; Kazmierski et al., 2018).

High-rate Precise Point Positioning technique gives the opportunity to measure ground movement with the Global Positioning System without any reference stations. This technique is increasingly used to observe big and moderate natural earthquakes (Avallone et al., 2011; Mendoza et al., 2012; Xu et al., 2013; Li et al., 2014; Melgar et al., 2015; Hung et al., 2017).

Except sampling frequency, the main difference between conventional GPS positioning and high-rate GPS dedicated to analysing geophysical signals is the observation length. In commonly used applications, there are estimated daily or weekly positions, while in high-rate positioning - short time series are analysed to obtain epoch-to-epoch positions. Due to short period of time high-rate PPP can be more precise than traditional PPP, reaching accuracies of few millimetres (Hefty and Gerhátová, 2012; Xu et al., 2013). Nowadays models applied to observations during PPP processing ensure that the majority of errors are modelled and within short period of time most of residual systematic errors are negligibly small (Shu et al., 2017). There are two errors in high-rate GPS-PPP processing that should be specially treated: satellite clock error and multipath error. Since satellite clock drifts over few minutes can be large, the most high-rate clock corrections should be used. For GPS observations these are 5-s clock corrections from the Center for Orbit Determination in Europe (CODE), 


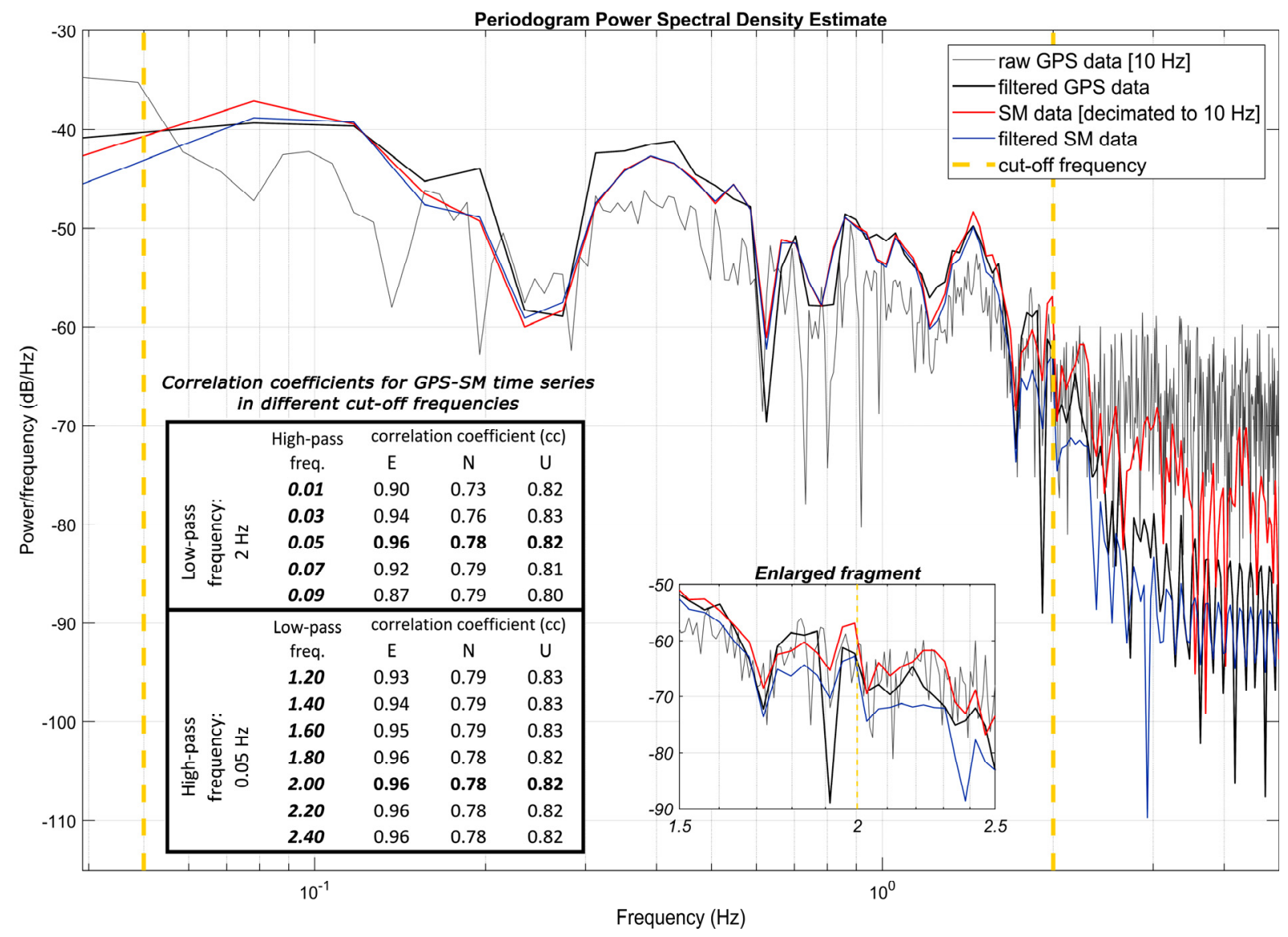

Fig. 6 Example periodogram of power density estimate for east displacement of station GUMA and GPS-SM displacements correlation coefficients obtained with different cut-off frequencies.

which should be interpolated to high-rate GPS applications (Shu et al., 2017). The second error is caused by multipath effect. In most common seismogeodetic approaches, the sidereal filtering concept is applied (e.g. Bock et al., 2000; Choi et al., 2004; Larson et al., 2007). In general it assumes that since the multipath effect is related to the geometry of the satellites, which repeats every sidereal period $(23 \mathrm{~h} 56 \mathrm{~m} 4 \mathrm{~s})$, this effect may be reduced by correcting the data by subtracting the residuals of coordinates or observables of the preceding days for each epoch.

\subsection{CALCULATION OF GPS-DERIVED POSITION TIME SERIES}

In this study, the high-rate GPS data was first processed with the RTKlib ver. 2.4.3 software (Takasu, 2009). This open-source software was also used in high-rate GNSS processing for example by Hung et al. (2017) and Michel et al. (2017). We used kinematic Precise Point Positioning mode with ionosphere-free L3 frequency combination and a 5hour of observations processing window. Final CODE orbits and 5-second GPS satellite clock, $15^{\circ}$ satellite elevation mask, earth rotation parameters and differential code biases were used. During processing an average of 7-8 satellites was used. Received geocentric Cartesian coordinates (XYZ) were subsequently transformed to the local topocentric Cartesian coordinates and to displacements. Next, the time series were clipped to 20-100 seconds time series depending on the time of waves' arrival and the event length to analyse the moment of the earthquake.

An example of the nonfiltered GPS position time series for the analysed Nepal earthquake is presented in Figure 5.

Since our goal was to use only short - 5-hour long - period of observations we did not applied sidereal filtering to reduce multipath effect. However we decided to test the application of band-pass digital filtering described by Kamatham et al. (2013), who observed that by applying digital filters of different cut- off frequencies over the spectrum of the multipath, one can significantly reduce the multipath errors. This approach enabled to reduce highfrequency noise error and possible low-frequency fluctuations (Fig. 7).

Here different types of digital filters were also tested and it was found that the Butterworth filter reduces the error most effectively in terms of noise and results in the highest correlation coefficient in comparison with seismic waveform. Moreover the Butterworth filter is characterized by flat passband, so it does not distort the signal. Higher-order Butterworth filters were also tested; however, they were found not to improve the results. Therefore, in this study, a 2-order Butterworth band-pass filter was designed with cut-off frequencies adjusted to each GPS station separately. In general, the seismic signal frequency decreases with the epicentral distance, but it 

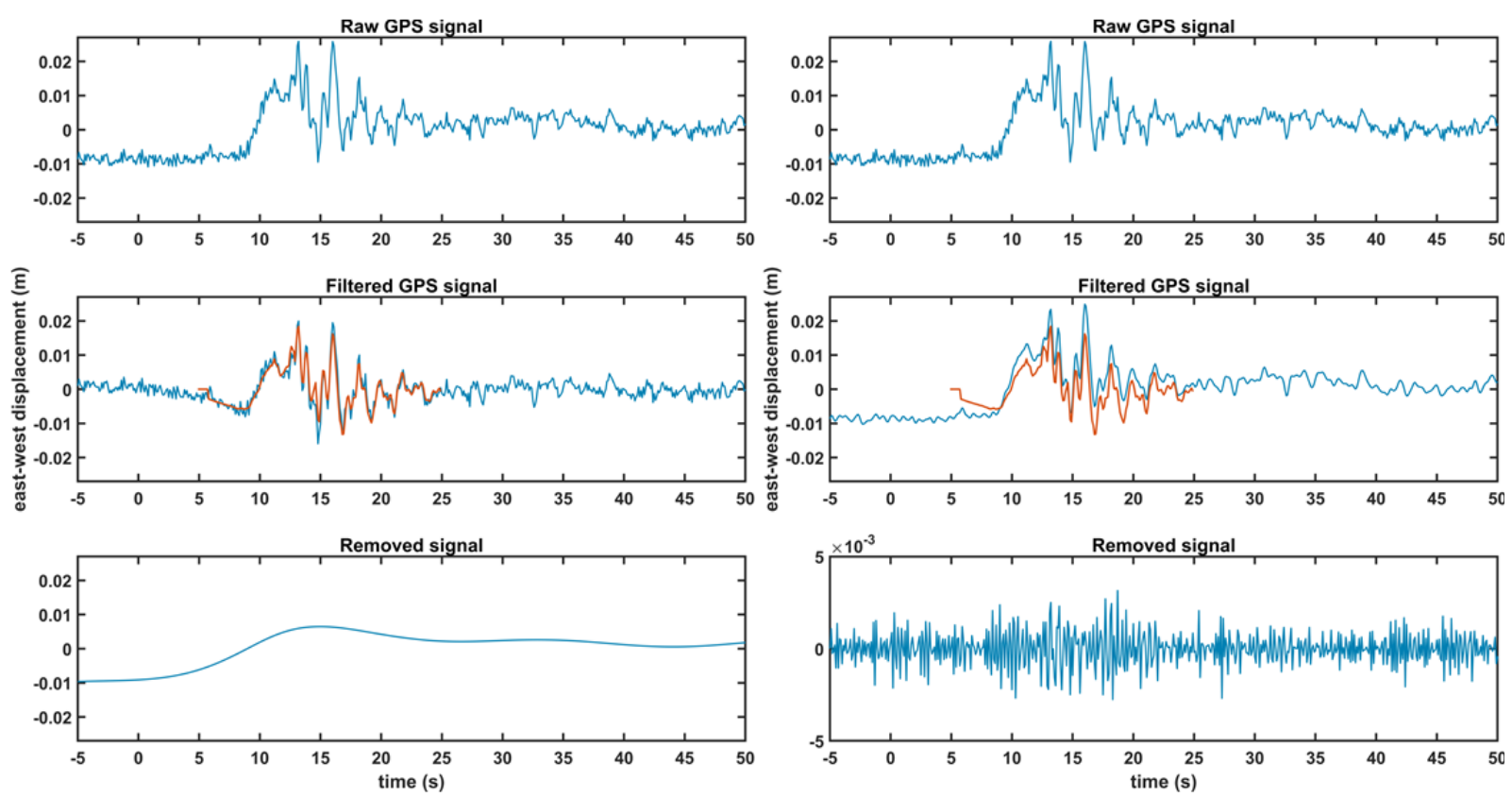

Fig. 7 Visso earthquake east-west dynamic displacements recorded by the GUMA GPS station (black) compared to SM displacement (grey). Left is the removal of the low-frequency PPP fluctuation; the cutoff frequency is $0.05 \mathrm{~Hz}$. Right is the removal of the high-frequency noise; the cut-off frequency is $2 \mathrm{~Hz}$.

is also dependent on ground characteristics and seismic wave propagation direction. In this study, for the Italian GPS station, the lower cut-off frequency was between $0.05-0.15 \mathrm{~Hz}$ and the higher was in the range of 1-2 $\mathrm{Hz}$, depending on the GPS station and considering the Nyquist frequency of $5 \mathrm{~Hz}$ for the data collected with 10 samples per second. The example of frequency analysis for GUMA station is visible in Figure 6. The cut-off frequency was chosen empirically considering the signal power and amplitude in the frequency domain and maximising the correlation coefficient between seismogram and GPSgram. In this case, highest correlation coefficient is obtained with high-pass cut-off frequency of 0.05 $\mathrm{Hz}$ and low-pass cut-off frequency in the range of 1.6$2.4 \mathrm{~Hz}$, where the mean correlation coefficient value is equal to $0.855 \pm 0.001$. The example of using a 2 order Butterworth filter with distinction on high- and low-frequencies rejection is shown in Figure 7.

In case of earthquakes, the cut-off frequencies should be chosen with particular attention so as not to eliminate the seismic signal. Nevertheless, the undoubted disadvantage of high-pass filtering GPS data is losing the information about static displacement, but it enables to compare GPS results with SM data. On the other hand, to calculate longterm displacements from GPS, it is not necessary to have such high rate data. Using digital filtering is widely used in processing recordings from strongmotion accelerograms (Boore and Bommer, 2005). There is the same problem with losing long-term displacements while processing acceleration or velocity data from strong-motion instruments with band-pass filter and then integrating it into displacements.

\section{GPS AND SM DISPLACEMENTS COMPARISON}

To compare SM and GPS displacements, unification of the units and sampling frequency of both time series is required. Therefore SM waveform was decimated to $5 \mathrm{~Hz}$ and $10 \mathrm{~Hz}$, which response to GPS receivers sampling frequency for Nepal and Italian earthquakes, respectively. It has been verified that decimation of the seismic signal to the GPS sampling frequency does not distort the signal and allows to compare both time series (eg. Psimoulis et al., 2015). The characteristics of nonfiltered, decimated and filtered position time series are similar in passband (Fig. 6). Therefore in signals comparison decimated SM time series interpolated to GPS-derived time samples are used. The performed procedure made it possible to calculate the Pearson correlation coefficients for each co-located pair of GPS-SM stations.

The time series of displacements from seismic and GPS data were compared in terms of peak ground displacement (PGD - maximum absolute displacement during the event) and peak-to-peak amplitudes (maximum-minimum displacement difference). Moreover, on co-located GPS-SM stations, the agreement of the polarity of P-wave first vertical motion was read from waveforms. Furthermore, the impact of epicentral distance and azimuth to measured GPS-derived displacement (GPS-displacement) was analysed by comparing the size of GPS-derived peak ground displacement from various stations and taking into account the focal mechanism of a specified event, which suggest the expected effects of seismic wave propagation.

Nevertheless, GPS-derived displacement is absolute and reflects short- and long-term motion, 

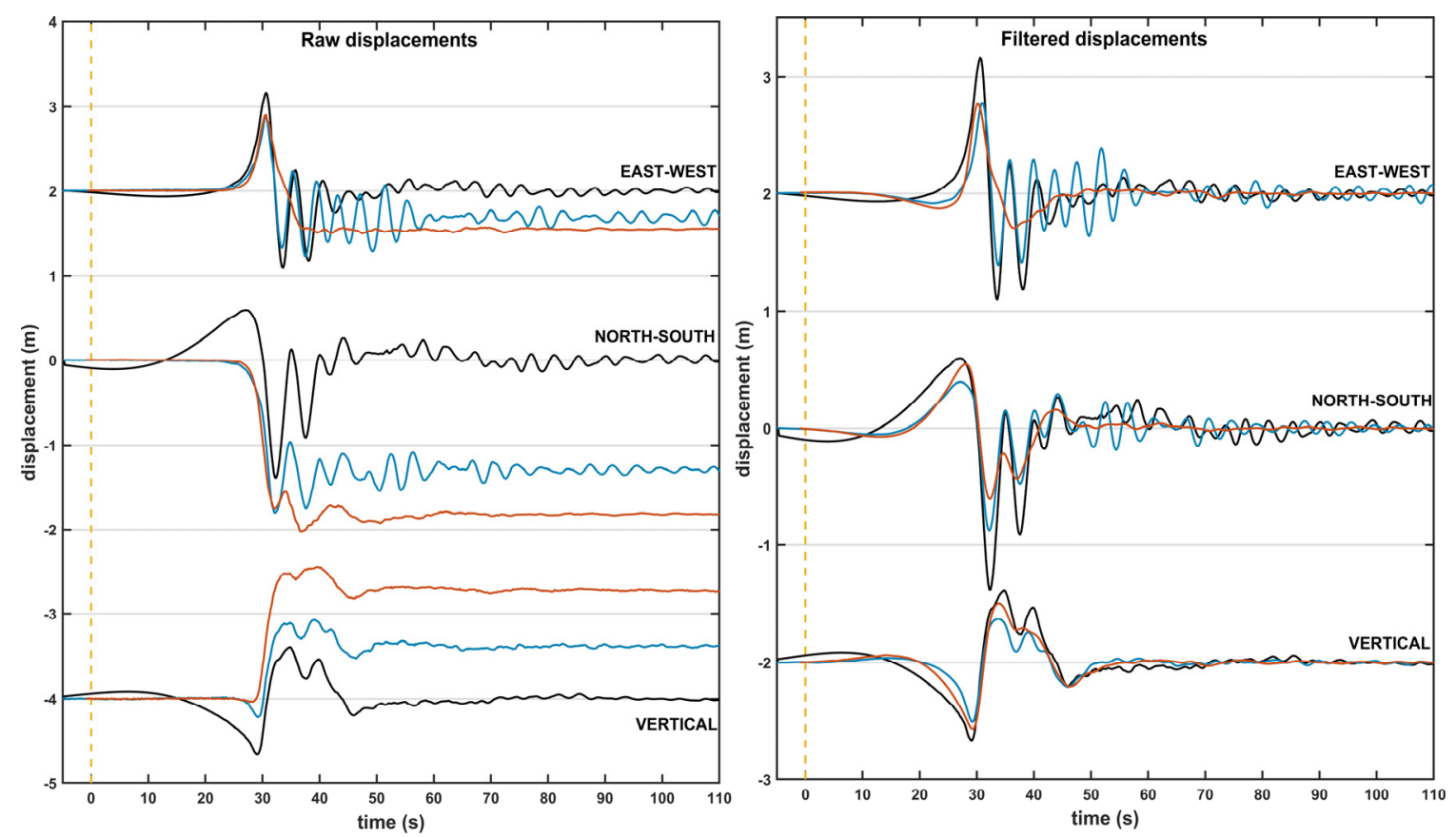

Fig. 8 Nepal earthquake NAST/KKN4/KATN displacements: left - NAST GPS-station nonfiltered E, N, U displacements, KKN4 and KATN accelerograph calculated displacements; right - NAST, KKN4 and KATN dynamic displacement with reduced the permanent displacement recorded by GPS station. The reference zero time is the time of the main shock.

while SM data is relative and seismic sensors return to the balance after the event. During the analysed Nepal earthquake, there occurred permanent displacement of about 1-2 meters on the near-source area, and GPS and seismic-derived displacement time series differ significantly. Since the seismic displacement is first integrated from acceleration and then usually corrected with digital filtering, as a result information about a permanent displacement is lost because of reducing low frequencies. Therefore, to compare the data the correction of GPS-displacement time series was needed by removing the permanent displacement with a high-pass Butterworth filter. The example of nonfiltered and detrended displacement time series of NAST GPS-station together with seismic displacements of KATN accelerograph are presented in Figure 8.

\subsection{REDUCING THE PERMANENT DISPLACEMENT IN THE EXAMPLE OF THE GORKHA EARTHQUAKE}

In the Nepal earthquake, two stations were compared with a KATN accelerograph as relatively co-located - the distance between sensors was $6 \mathrm{~km}$ (NAST) and $10 \mathrm{~km}$ (KKN4), but with a similar epicentral azimuth. For this purpose, the time series were time aligned and permanent displacement was reduced with removing low frequencies. The correlation coefficients between nonfiltered GPS data and processed SM data on the time of 100 seconds after the event occurred, are in the range of 0.40-0.65 for the NAST station and $0.34-0.43$ for the KKN4 station. The application of band-pass filtering, where the frequencies below $0.03 \mathrm{~Hz}$ and over $0.4 \mathrm{~Hz}$ are removed, allow for improving the compatibility between time series by $20-73 \%$ to correlation coefficient values of $0.79-0.92$ for the NAST station and $0.70-0.96$ for the KKN4. Detailed correlation coefficient values are presented in Table 3 and the waveforms are presented in Figure 8. In this earthquake, KKN4 and NAST GPS stations are examples of the fact that dynamic movement strongly depends on the ground structure. This is clearly seen in displacement waveforms (Fig. 8), especially for horizontal movement. The KKN4 station is located on hard rocks, while the NAST and KATN stations are situated on soft sediment (Galetzka et al., 2015).

Correlation coefficient values show a significant relationship between time series obtained from different sensors. Moreover, the displacement waveforms show different wave lengths registered by GPS and accelerograph, since GPS register ground response for seismic waves, which are directly recorded by strong-motion instruments. The correlation between SM and GPS displacement time series differ depending on distance and ground type. Station KKN4 is situated further from KATN than NAST, but closer to the epicentre. Therefore, the peak ground displacement at KKN4 is bigger than at the NAST station.

Estimated GPS displacements of 5 GPS stations (SYBC, SNDL, RMTE, NAST, KKN4) were also compared with those obtained by Galetzka et al. (2015) and the mean relative residual difference of peak ground displacement is $3.4 \%$, which is equal to $1.5 \mathrm{~cm}$ of mean PGD.

Although the distance between NAST and KKN4 is $16.7 \mathrm{~km}$, the agreement between GPS time 
Table 3 Correlation coefficient values of GPS and seismometer displacement time series.

\begin{tabular}{|c|c|c|c|c|c|c|c|c|c|c|}
\hline \multirow[t]{2}{*}{ EQ } & \multirow[t]{2}{*}{$\begin{array}{c}\text { Pair of sensors } \\
\text { GPS/SM }\end{array}$} & \multicolumn{3}{|c|}{$\begin{array}{c}\text { Nonfiltered GPS } \\
\text { time series }\end{array}$} & \multicolumn{3}{|c|}{$\begin{array}{c}\text { Band-pass filtered GPS } \\
\text { time series }\end{array}$} & \multicolumn{3}{|c|}{ Percentage change } \\
\hline & & $\mathrm{E}$ & $\mathrm{N}$ & $\mathrm{U}$ & $\mathrm{E}$ & $\mathrm{N}$ & $\mathrm{U}$ & $\mathrm{E}$ & $\mathrm{N}$ & $\mathrm{U}$ \\
\hline \multirow[t]{2}{*}{ Gorkha } & KKN4/KATN & 0.44 & 0.34 & 0.43 & 0.70 & 0.87 & 0.96 & $38 \%$ & $61 \%$ & $55 \%$ \\
\hline & NAST/KATN & 0.63 & 0.40 & 0.51 & 0.79 & 0.90 & 0.92 & $20 \%$ & $55 \%$ & $45 \%$ \\
\hline \multirow[t]{4}{*}{ Visso } & ACCU/ACC & 0.61 & 0.27 & 0.22 & 0.95 & 0.39 & 0.77 & $36 \%$ & $31 \%$ & $72 \%$ \\
\hline & AMAT/AMT & 0.73 & 0.19 & 0.67 & 0.80 & 0.52 & 0.78 & $8 \%$ & $63 \%$ & $14 \%$ \\
\hline & GUMA/GUMA & 0.87 & 0.71 & 0.81 & 0.96 & 0.78 & 0.82 & $9 \%$ & $9 \%$ & $2 \%$ \\
\hline & MTER/RM33 & 0.37 & 0.20 & 0.33 & 0.80 & 0.57 & 0.49 & $54 \%$ & $65 \%$ & $32 \%$ \\
\hline \multirow[t]{6}{*}{ Norcia } & $\mathrm{ACCU} / \mathrm{ACC}$ & 0.82 & 0.26 & 0.57 & 0.96 & 0.78 & 0.75 & $14 \%$ & $67 \%$ & $24 \%$ \\
\hline & AMAT/AMT & 0.72 & 0.57 & 0.66 & 0.77 & 0.67 & 0.67 & $7 \%$ & $15 \%$ & $1 \%$ \\
\hline & ATTE/ATTE & 0.89 & 0.23 & 0.66 & 0.93 & 0.34 & 0.67 & $4 \%$ & $33 \%$ & $1 \%$ \\
\hline & CAPE/CPS & 0.84 & 0.59 & 0.58 & 0.94 & 0.72 & 0.72 & $11 \%$ & $18 \%$ & $19 \%$ \\
\hline & LTNA/LAT & 0.96 & 0.82 & 0.37 & 0.99 & 0.90 & 0.40 & $3 \%$ & $8 \%$ & $8 \%$ \\
\hline & MUVI/T1216 & 0.62 & 0.40 & 0.31 & 0.84 & 0.60 & 0.59 & $26 \%$ & $33 \%$ & $47 \%$ \\
\hline
\end{tabular}

series reaches correlation coefficients of 0.83 for the east component, 0.95 for the north component and 0.98 for vertical one. The time difference between seismic waves arrival was almost 4 seconds.

\subsection{CO-LOCATED GPS VS SM DISPLACEMENT TIME SERIES COMPARISON}

After filtering the GPS time series of two Italian earthquakes, analysis of correlation coefficients was performed. The agreement between sensors strongly depends on the distance between them, the noise level and characteristics of the ground on which the stations are located. Analysed stations are located in different epicentral distances and azimuths. The amplitudes on analysed stations in the Visso earthquake were about $2 \mathrm{~cm}$, while in the Norcia earthquake they ranged from $1 \mathrm{~cm}$ to $20 \mathrm{~cm}$.

The correlation coefficient varies depending on epicentral azimuth and displacement rate. In the Visso earthquake, for the closest three stations (ACCU, AMAT, GUMA) there is a strong correlation in the east and up direction, whereas in the north direction, only a strong correlation for the GUMA station is visible. Not evident correlation in north direction is probably related to focal mechanism of event and stations location. The worst correlation coefficients were calculated for the MTER station, which is the furthest from the epicentre and in a slightly different azimuth than the others. Compared waveforms are presented in Figures 9 and 10 correlation coefficients are listed in Table 3 . In the Norcia earthquake, the agreement between co-located GPS-SM stations is greater than in the Visso event. Analysed stations are in different epicentral distances. GPS results from the closest stations (MUVI, AMAT, ACCU) show a strong agreement with SM data, indicated by correlation coefficients in the range of 0.59-0.96. For medium-distance station-pairs (ATTE, CAPE), the agreement is about 0.7 for the vertical component and 0.9 in the east direction, with one north direction outlier (the ATTE station) with a correlation coefficient of 0.34 . In the furthest station
(LTNA), located $152 \mathrm{~km}$ away from the epicentre - in both waveforms surface waves are visible in a very good horizontal agreement (correlation coefficients 0.99 and 0.90 ). In both events, the weakest obtained correlation is for the north-south component.

Table 4 presents a comparison of SM and filtered GPS peak ground displacements. For Italian events, the GPS-SM absolute value of average PGD difference is $6 \mathrm{~mm}$ with up to $2.14 \mathrm{~km}$ distances between devices. The GPS-SM co-location distances for the Nepal event greater than $6 \mathrm{~km}$ together with a stronger earthquake caused the PGD differences to increase by $0.64 \mathrm{~m}$ on average.

To assess the quality of GPS time series the RMS was calulated, assuming the stability of station before and after the earthquake. RMS of analysed GPS time series before an earthquake is in the order of a few millimetres. During an event, RMS depends on the magnitude, reaching an average of $14.2 \mathrm{~cm}$ in the Nepal earthquake and an average of $8 \mathrm{~mm}$ in Italian earthquakes, which is similar to RMS values of seismological time series.

In all analysed earthquakes, the agreement between GPS-derived and SM displacement waveforms in terms of the first P-arrival polarity was manually checked and it was found that it is consistent in all cases. This confirms the GNSS technique capability for determining fault plane solution (e.g. Zheng et al., 2012). Figures 9 and 10 show this agreement as well as the fact that GPS-derived threedimensional displacements are usually underestimated. This is also confirmed in peak-to-peak amplitudes comparison, especially in the vertical direction, which is always the weakest GPS estimated coordinate.

\subsection{DISPLACEMENT RELATIONSHIP WITH THE AZIMUTH AND FOCAL MECHANISM}

For the Nepal earthquake, we have processed data from 8 GPS stations obtaining displacements. The agreement of the polarity of P-wave first vertical motion was read from waveforms, clearly visible in 
Table 4 Peak ground displacements for co-located GPS-SM stations with filtering cut-off frequencies.

\begin{tabular}{|c|c|c|c|c|c|c|c|c|c|c|c|c|c|}
\hline \multirow{3}{*}{$E Q$} & \multirow{2}{*}{\multicolumn{2}{|c|}{ SENSOR ID }} & \multirow{2}{*}{\multicolumn{2}{|c|}{$\begin{array}{c}\text { CUT-OFF } \\
\text { FREQUENCY } \\
{[\mathrm{Hz}]}\end{array}$}} & \multicolumn{9}{|c|}{ PEAK GROUND DISPLACEMENT [m] } \\
\hline & & & & & \multicolumn{3}{|c|}{ SM } & \multicolumn{3}{|c|}{ GPS } & \multicolumn{3}{|c|}{ PGD difference } \\
\hline & GPS & SM & LOW & HIGH & $\mathbf{E}$ & $\mathbf{N}$ & $\mathbf{U}$ & $\mathbf{E}$ & $\mathbf{N}$ & $\mathbf{U}$ & $\mathbf{E}$ & $\mathbf{N}$ & $\mathbf{U}$ \\
\hline \multirow{2}{*}{ Gorkha } & KKN4 & $4 T$ & 0.03 & 040 & 1.27 & 2.067 & 108 & 1.07 & 1.06 & & -0.209 & -1.007 & -0.837 \\
\hline & NAST & KATN & 03 & 0.40 & & 2.067 & 1. & 0.877 & 1.3 & 1 & 02 & -0.680 & -0.721 \\
\hline \multirow{4}{*}{ (VIsso) } & GUMA & & & & & & & & & & & & \\
\hline & $\mathrm{ACCU}$ & & & & & 0.008 & & & & & & -0.002 & 005 \\
\hline & AMAT & & 0.15 & 2.00 & & 0.029 & & 19 & 15 & & 0.001 & -0.004 & 0.007 \\
\hline & MTER & & 0.15 & 1.00 & 0.005 & 0.003 & 0.002 & 0.005 & 0.004 & 0.004 & 0.000 & 0.001 & 0.002 \\
\hline \multirow{6}{*}{$\begin{array}{c}\text { Italy } 2 \\
\text { (Norcia) }\end{array}$} & MUVI & & 0.05 & & & 0.103 & & 0.133 & 0.072 & 0.101 & -0.009 & -0.031 & -0.003 \\
\hline & $\mathrm{ACCU}$ & & & & & 0.075 & & & & & & -0.028 & 0.041 \\
\hline & AMAT & & & & & 0.008 & & & & & & & 03 \\
\hline & ATTE & & & & & & & & & & & & 0.003 \\
\hline & & & & & & & & & & & & & 0.008 \\
\hline & $\mathrm{LT}$ & IT.LAT & 05 & 1.00 & 0.055 & 0.051 & 0.030 & 0.046 & 0.026 & 0.046 & -0.009 & -0.025 & 0.016 \\
\hline \multicolumn{5}{|c|}{ Average } & 0.242 & 0.371 & 0.352 & 0.191 & 0.223 & 0.229 & -0.051 & -0.148 & -0.123 \\
\hline \multicolumn{5}{|c|}{ 4verage without Nepal event } & 0.035 & 0.032 & 0.025 & 0.035 & 0.023 & 0.034 & 0.000 & -0.009 & 0.009 \\
\hline
\end{tabular}
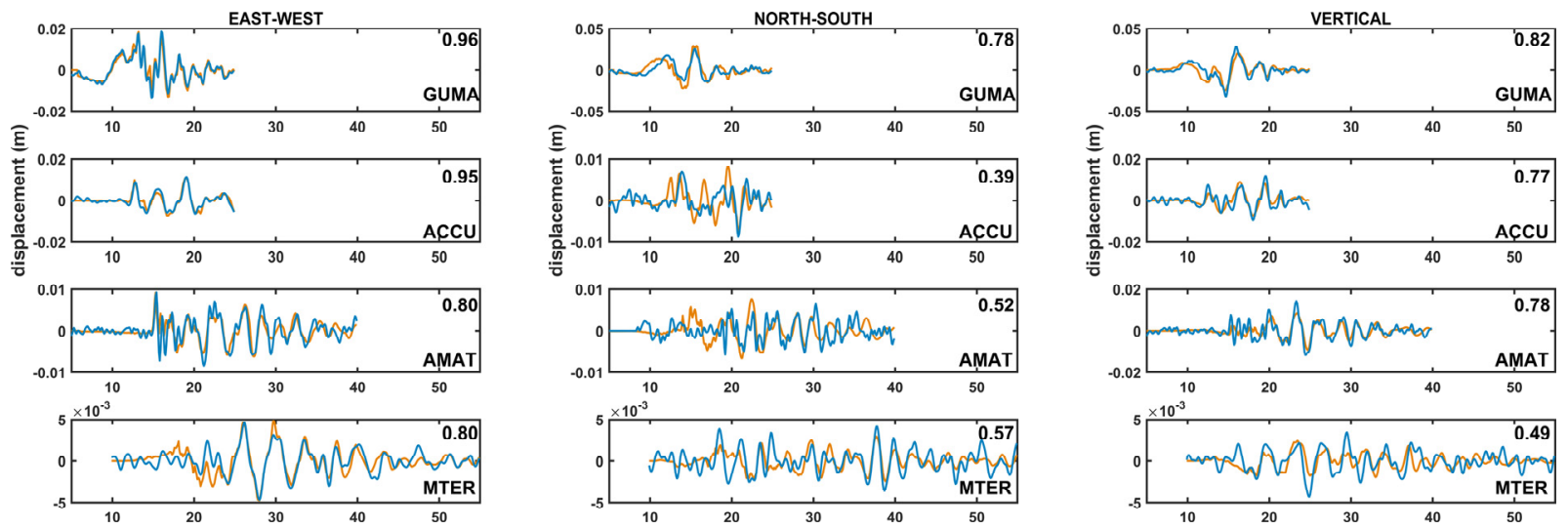

Fig. 9 GPS (black) and SM (grey) displacement time series of the Visso earthquake cropped to analysed time with inter-technique correlation coefficients.
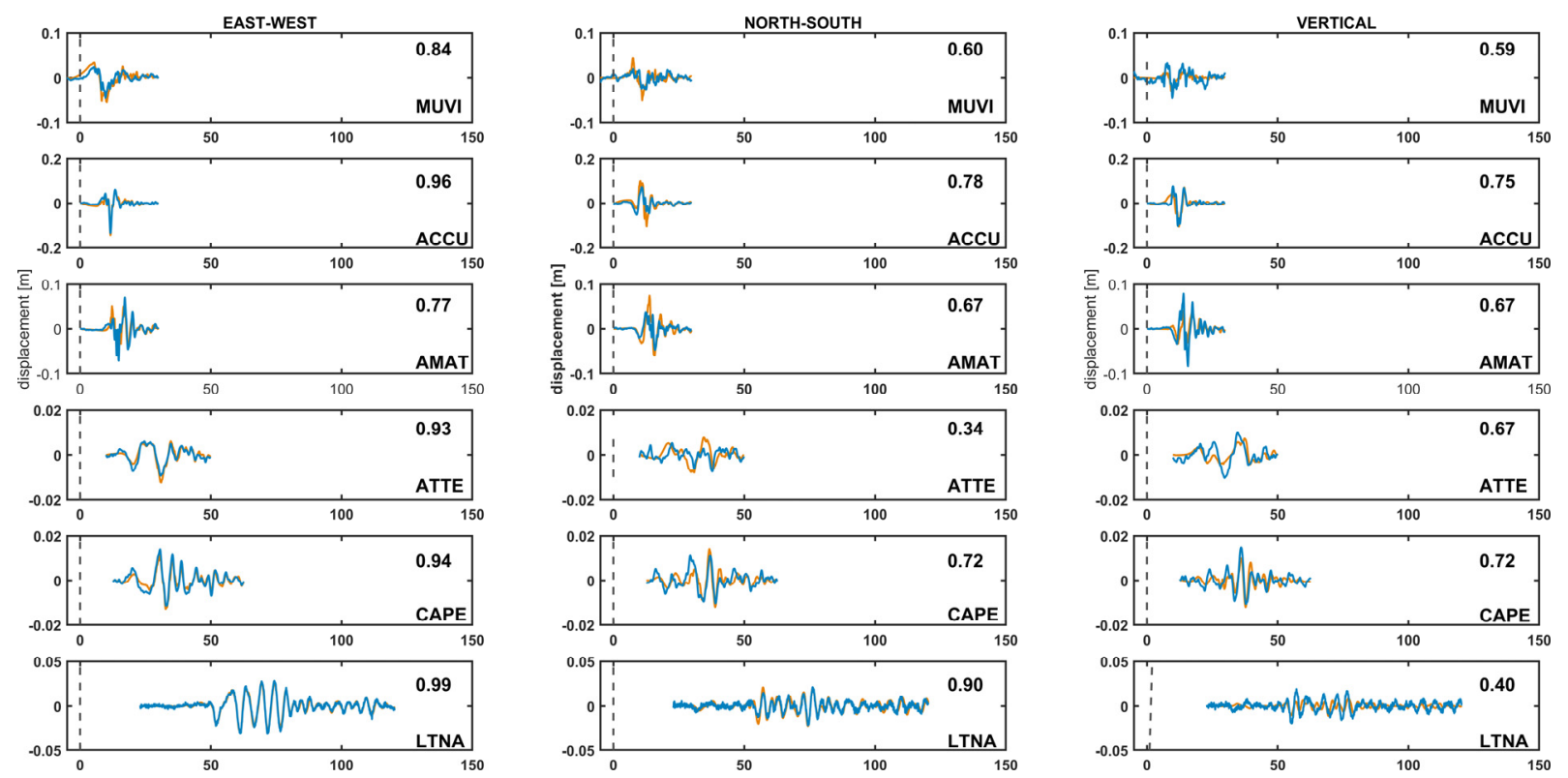

Fig. 10 GPS (black) and SM (grey) displacement time series of the Norcia earthquake cropped to analysed time with inter-technique correlation coefficients. 
Figure 5 - stations located SW from epicentre were uplifted due to dilational forces, while stations located NE from epicentre were subsided due to compressional forces. It is worthwhile to distinguish the two characteristic groups of stations in relation to their epicentral azimuth. The first group includes the DNSG and GRHI stations which are situated west of the fault area (Fig. 5). At these stations, GPS-derived horizontal and vertical displacements don't exceed $5 \mathrm{~cm}$ and $8 \mathrm{~cm}$, respectively, due to the position outside of the source area and maximum slip direction towards SSW according to finite fault models provided by USGS and other authors (e.g. Wang and Fialko, 2015). The next group includes 3 GPS stations (KKN4, NAST, SNDL) and the accelerograph (KATN) located on the top of the fault zone or to the south, slightly outside the source area. All these stations were elevated during earthquakes. The RMTE station located SE from the source was also elevated. On the other hand, stations located in the north-east epicentral direction (CHLM, SYBC) were subsided. This up-down movement agrees with the focal mechanism and finite source models which state that in the north direction from the source area, the compressional forces should cause the subsidence and in the S-SSE direction, the dilatational forces should cause the uplift. At the similar epicentral azimuth, the displacement value decreases with the epicentral distance. It is especially seen on the $127^{\circ} \mathrm{SE}$ azimuth, where waves amplitudes were enhanced (Duputel et al., 2016).

In the case of the 2016 Italian events, focal mechanisms were similar normal faults with an NNW-SSE strike (difference up to $7^{\circ}$ ) and GPS sensors were located in similar azimuths and distances from the epicentres. During the Visso earthquake, GPS peak ground displacements reached values between 4-14 $\mathrm{mm}$ for stations located south-east from the epicentre and reached $25 \mathrm{~mm}$ horizontally and $32 \mathrm{~mm}$ vertically for the GUMA station located northeast from the epicentre. In addition, the GUMA station showed the best correlation with the accelerograph. During the Norcia earthquake, all stations were located south-east and north-west from the epicentre in the azimuths similar to the strike angle of the nodal plane (the angle between the line created by the intersection of rupture plane and the north direction). Peak ground displacement values were in the range of $0.7 \mathrm{~cm}$ to $13.3 \mathrm{~cm}$.

\section{CONCLUSIONS}

This study presents that the sensitivity of GPS PPP kinematic high-rate positioning with position domain filtering using a band-pass Butterworth filter on small samples of position time series is enough to obtain dynamic co-seismic displacements in good agreement with SM data and produce reliable waveforms. Three earthquakes with magnitudes over 6.1 with 12 pairs of co-located GPS stations and accelerographs were analysed. The average correlation coefficient after applying filtration increased from 0.54 to 0.75 . This demonstrates that PPP position estimates fluctuation (sidereal effect) and noise can be successfully reduced with the bandpass filtering. However, as SM displacements are integrated from velocities or accelerations and GPS displacements are measured directly, GPS sensors are supplementary devices to analyse ground movements in terms of displacement (eg. Zheng et al., 2012; Avallone et al., 2016). The correlation between GPS and SM displacements depends on ground characteristics, epicentral azimuth and distance, and is different for each direction. The biggest agreement occurs when both sensors are located in a similar epicentral azimuth. Results shown in this work confirm that the displacement polarity and values may be useful in focal mechanism and finite fault model validation as an independent data source. Future work will be focused on noise reduction from high-rate GNSS derived time series and investigation of highrate GNSS processing parameter influence as well as further studies on combining GNSS and SM technologies.

\section{ACKNOWLEDGEMENTS}

This paper was carried out within EPOS European Plate Observing System co-financed by the European Union from the funds of the European Regional Development Fund POIR.04.02.00-14A0003/16. Seismic waveform data for this study were downloaded through the Center for Engineering Strong Motion Data (CESMD) and The ITalian ACcelerometric Archive by INGV. GPS data for the Nepal earthquake are available through the UNAVCO website and GPS data for the Italian earthquakes are available at the following link: ftp://gpsfree.gm.ingv.it/amatrice2016/hrgps/. This work has been supported by the Wroclaw Center of Networking and Supercomputing (http://www.wcss.wroc.pl): computational grant using MATLAB Software License No: 101979.

\section{REFERENCES}

Avallone, A., Latorre, D., Serpelloni, E., Cavaliere, A., Herrero, A., Cecere, G., D'Agostino, N., D'Ambrosio, C., Devoti, R., Giuliani, R., Mattone, M., Calcaterra, S., Gambino, P., Abruzzese, L., Cardinale, V. et al.: 2016, Coseismic displacement waveforms for the 2016 August 24 Mw6.0 Amatrice earthquake (central Italy) carried out from high-rate GPS data. Ann. Geophys., 59, 5. DOI: 10.4401/ag-7275

Avallone, A., Marzario, M., Cirella, A., Piatanesi, A., Rovelli, A., Di Alessandro, C., D'Anastasio, E., D'Agostino, N., Giuliani, R. and Mattone, M.: 2011, Very high rate $(10 \mathrm{~Hz})$ GPS seismology for moderatemagnitude earthquakes: The case of the Mw 6.3 L'Aquila (central Italy) event. J. Geophys. Res. Solid Earth, 116, B02305. DOI: 10.1029/2010JB007834

Avouac, J.-P. et al.: 2015, Caltech Tectonics Observatory Nepal Network - NEGAR - GRHI P.S. UNAVCO, GPS/GNSS Observations DataSet. DOI: 10.7283/T5VH5M03 
Bock, Y. and Melgar, D.: 2016, Physical applications of GPS geodesy: A review. Rep. Prog. Phys., 79, 10. DOI: $10.1088 / 0034-4885 / 79 / 10 / 106801$

Bock, Y., Nikolaidis, R.M., de Jonge, P.J. and Bevis, M.: 2000, Instantaneous geodetic positioning at medium distances with the Global Positioning System. J. Geophys. Res. Solid Earth, 105, B12, 28223-28253. DOI: $10.1029 / 2000 J B 900268$

Boore, D.M.: 2001, Effect of baseline corrections on displacements and response spectra for several recordings of the 1999 Chi-Chi, Taiwan, earthquake. Bull. Seism. Soc. Am., 9, 5, 1199-1211. DOI: $10.1785 / 0120000703$

Boore, D.M. and Bommer, J.J.: 2005, Processing of strongmotion accelerograms: Needs, options and consequences. Soil Dyn. Earthq. Eng., 25, 2, 93-115. DOI: 10.1016/j.soildyn.2004.10.007

Choi, K., Bilich, A., Larson, K.M. and Axelrad, P.: 2004, Modified sidereal filtering: Implications for high-rate GPS positioning. Geophys. Res. Lett., 31, 22, 1-4. DOI: $10.1029 / 2004$ GL021621

Colosimo, G., Crespi, M. and Mazzoni, A.: 2011a, Realtime GPS seismology with a stand-alone receiver: A preliminary feasibility demonstration. J. Geophys. Res. Solid Earth, 116, B11302. DOI: 10.1029/2010JB007941

Colosimo, G., Crespi, M., Mazzoni, A. and Dautermann, T.: 2011b, Co-seismic displacement estimation: Improving tsunami early warning systems. GIM International, 25, 5.

Dreger, D.S., Huang, M.-H., Rodgers, A., Taira, T. and Wooddell, K.: 2015, Kinematic Finite-Source Model for the 24 August 2014 South Napa, California, earthquake from joint inversion of seismic, GPS, and InSAR data. Seism. Res. Lett., 86, 2A, 327-334. DOI: $10.1785 / 0220140244$

Duputel, Z., Vergne, J., Rivera, L., Wittlinger, G., Farra, V. and Hetényi, G.: 2016, The 2015 Gorkha earthquake: A large event illuminating the Main Himalayan Thrust fault. Geophys. Res. Lett., 43, 6, 2517-2525. DOI: 10.1002/2016GL068083

Elliott, J.R., Nissen, E., England, P.C., Jackson, J.A., Lamb, S., Li, Z., Oehlers, M. and Parsons, B.E.: 2011, Slip in the 2010-2011 Canterbury earthquakes, New Zealand and implications for future seismic hazard in Christchurch. AGU Fall Meeting Abstracts, 1, No. B3, 2.

Emore, G.L., Haase, J.S., Choi, K., Larson, K.M. and Yamagiwa, A.: 2007, Recovering seismic displacements through combined use of 1-Hz GPS and strong-motion accelerometers. Bull. Seism. Soc. Am., 97, 2, 357-378. DOI: 10.1785/0120060153

Feng, G., Li, Z., Shan, X., Zhang, L., Zhang, G. and Zhu, J.: 2015, Geodetic model of the 2015 April 25 M w 7.8 Gorkha Nepal earthquake and $\mathrm{Mw} 7.3$ aftershock estimated from InSAR and GPS data. Geophys. J. Int., 203, 2, 896-900. DOI: 10.1093/gji/ggv335

Fratarcangeli, F., Ravanelli, M., Mazzoni, A., Colosimo, G., Benedetti, E., Branzanti, M., Savastano, G., Verkhoglyadova, O., Komjathy, A. and Crespi, M.: 2018a, The variometric approach to real-time highfrequency geodesy. Rendiconti Lincei, Scienze e Naturalli, 29, 3, 95-108. DOI: $10.1007 / \mathrm{s} 12210-018-0708-5$

Fratarcangeli, F., Savastano, G., D’Achille, M.C., Mazzoni, A., Crespi, M., Riguzzi, F., Devoti, R. and Pietrantonio, G.: 2018b, VADASE reliability and accuracy of real-time displacement estimation: Application to the Central Italy 2016 earthquakes. Remote Sens., 10, 8, 1201. DOI: 10.3390/rs10081201

Galetzka, J., Melgar, D., Genrich, J.F., Geng, J., Owen, S., Lindsey, E.O., Xu, X., Bock, Y., Avouac, J.-P., Adhikari, L.B. and Others: 2015, Slip pulse and resonance of Kathmandu basin during the $2015 \mathrm{Mw}$ 7.8 Gorkha earthquake, Nepal imaged with geodesy. Science, 349, 6252, 1091-1095.

DOI: $10.1126 /$ science.aac6383

Genrich, J.F. and Bock, Y.: 2006, Instantaneous geodetic positioning with $10-50 \mathrm{~Hz}$ GPS measurment: Noise characteristics and implications for monitoring networks. J. Geophys. Res. Solid Earth, 111, B3, B03403. DOI: 10.1029/2005JB003617

Hadaś, T.: 2015, GNSS-Warp Software for Real-Time Precise Point Positioning. Artificial Satellites, 50, 2, 59-76. DOI: 10.1515/arsa-2015-0005

Hadaś, T. and Bosy, J.: 2014, IGS RTS precise orbits and clocks verification and quality degradation over time. GPS Solut., 19, 1, 93-105.

DOI: $10.1007 / \mathrm{s} 10291-014-0369-5$

Hefty, J. and Gerhátová, L.: 2012, Potential of precise point positioning using $1 \mathrm{HZ}$ GPS data for detection of seismic-related displacements. Acta Geodyn. Geomater., 9, 3, 303-313.

Houlié, N., Dreger, D. and Kim, A.: 2014, GPS source solution of the 2004 Parkfield earthquake. Sci. Rep., 4, 3646. DOI: $10.1038 / \mathrm{srep} 03646$

Huang, Y., Yang, S., Qiao, X., Lin, M., Zhao, B. and Tan, K.: 2017, Measuring ground deformations caused by 2015 Mw7.8 Nepal earthquake using high-rate GPS data. Geodesy and Geodynamics, 8, 4, 285-291. DOI: $10.1016 /$ j.geog.2017.03.003

Hung, H.K. and Rau, R.J.: 2013, Surface waves of the 2011 Tohoku earthquake: Observations of Taiwan's dense high-rate GPS network. J. Geophys. Res. Solid Earth, 118, 1, 332-345. DOI: 10.1029/2012JB009689

Hung, H.K., Rau, R.J., Benedetti, E., Branzanti, M., Mazzoni, A., Colosimo, G. and Crespi, M.: 2017, GPS Seismology for a moderate magnitude earthquake: Lessons learned from the analysis of the 31 October 2013 ML6.4 Ruisui (Taiwan) earthquake. Ann. Geophys., 60, 5, S0553. DOI: 10.4401/ag-7399

Kamatham, Y., Sarma, A., Kumar, A. and Satyanarayana, K.: 2013, Spectral analysis and mitigation of GPS multipath error using digital filtering for static applications. IETE Journal of Research, 59, 2, 156166. DOI: $10.4103 / 0377-2063.113036$

Kazmierski, K., Hadas, T. and Sośnica, K.: 2018, Weighting of multi-GNSS observations in real-time precise point positioning. Remote Sens., 10, 1, 84. DOI: $10.3390 /$ rs 10010084

Kelevitz, K., Houlié, N., Giardini, D. and Rothacher, M.: 2017, Performance of high-rate GPS waveforms at long periods: Moment tensor inversion of the 2003 Mw8.3 Tokachi-Oki earthquake. Bull. Seism. Soc. Am., 107, 4, 1891-1903. DOI: 10.1785/0120160338

Kouba, J. and Héroux, P.: 2001, Precise Point Positioning using IGS Orbit and Clock Products. GPS Solut., 5, 2, 12-28. DOI: 10.1007/PL00012883

Larocca, A.P.C., de Araújo Neto, J.O., Trabanco, J.L.A., dos Santos, M.C. and Barbosa, A.C.B.: 2016, First steps using two GPS satellites for monitoring the dynamic behavior of a small concrete highway bridge. J. Surv. Eng., 142, 3. DOI: 10.1061/(ASCE)SU.1943-5428.0000170 
Larson, K.M.: 2009, GPS seismology. J. Geodesy, 83, 3-4, 227-233. DOI: $10.1007 / \mathrm{s} 00190-008-0233-\mathrm{x}$

Larson, K.M., Bilich, A. and Axelrad, P.: 2007, Improving the precision of high-rate GPS. J. Geophys. Res. Solid Earth, 112, 5, B05422. DOI: 10.1029/2006JB004367

Larson, K.M., Bodin, P. and Gomberg, J.: 2003, Using 1-Hz GPS data to measure deformations caused by the denali fault earthquake. Science, 300, 5624, 14211424. DOI: $10.1126 /$ science. 1084531

Li, X., Guo, B., Lu, C., Ge, M., Wickert, J. and Schuh, H.: 2014, Real-time GNSS seismology using a single receiver. Geophys. J. Int., 198, 1, 72-89. DOI: $10.1093 /$ gji $/$ ggu113

Luzi, L., Puglia, R., Russo, E. and OREFUS WG5: 2016, Engineering strong motion database, version 1.0. National Insitute of Geophysics and Volcanology (INGV), Observatories \& Research Facilities for European Seismology. DOI: 10.13127/ESM

Massonnet, D., Rossi, M., Carmona, C., Adragna, F., Peltzer, G., Feigl, K. and Rabaute, T.: 1993, The displacement field of the Landers earthquake mapped by radar interferometry. Nature, 364, 6433, 138-142. DOI: $10.1038 / 364138 \mathrm{a} 0$

Melgar, D., Bock, Y., Sanchez, D. and Crowell, B.W.: 2013, On robust and reliable automated baseline corrections for strong motion seismology. J. Geophys. Res. Solid Earth, 118, 3, 1177-1187. DOI: 10.1002/jgrb.50135

Melgar, D., Geng, J., Crowell, B.W., Haase, J.S., Bock, Y., Hammond, W.C. and Allen, R.M.: 2015, Seismogeodesy of the 2014 Mw6.1 Napa earthquake, California: Rapid response and modeling of fast rupture on a dipping strike-slip fault. J. Geophys. Res. Solid Earth, 120, 7, 5013-5033. DOI: $10.1002 / 2015 J B 011921$

Mendoza, L., Kehm, A., Koppert, A., Martín Dávila, J., Gárate, J. and Becker, M.: 2012, The Lorca earthquake observed by GPS: A test case for GPS seismology. Física de la Tierra, 24, 129-150. DOI: $10.5209 /$ rev FITE.2012.v24.40135

Mervart, L., Zdenek, L., Rocken, C. and Iwabuchi, T.: 2008, Precise Point Positioning with ambiguity resolution in real-time. Proc. ION GNSS 2008, Savanah, Georgia, 4, 2280-2288.

Michel, C., Kelevitz, K., Houlié, N., Edwards, B., Psimoulis, P., Su, Z., Clinton, J. and Giardini, D.: 2017, The potential of high-rate GPS for strong ground motion assessment. Bull. Seis. Soc. Am., 107, 4, 1849-1859. DOI: 10.1785/0120160296

Psimoulis, P., Houlié, N., Meindl, M. and Rothacher, M.: 2015, Consistency of PPP GPS and strong-motion records: Case study of Mw9.0 Tohoku-Oki 2011 earthquake. Smart Struct. Syst., 16, 2, 347-366. DOI: $10.12989 /$ sss.2015.16.2.347

Saunders, J.K., Goldberg, D.E., Haase, J.S., Bock, Y., Offield, D.G., Melgar, D., Restrepo, J., Fleischman, R.B., Nema, A., Geng, J., Walls, C., Mann, D. and Mattioli, G.S.: 2016, Seismogeodesy using GPS and low-cost MEMS accelerometers: Perspectives for earthquake early warning and rapid response. Bull. Seism. Soc. Am., 106, 6, 2469-2489. DOI: $10.1785 / 0120160062$
Shu, Y., Fang, R., Geng, J., Zhao, Q. and Liu, J.: 2018, Broadband velocities and displacements from integrated GPS and accelerometer data for high-rate seismogeodesy. Geophys. Res. Lett., 45, 17, 89398948. DOI: $10.1029 / 2018$ GL079425

Shu, Y., Shi, Y., Xu, P., Niu, X. and Liu, J.: 2017, Error analysis of high-rate GNSS Precise Point Positioning for seismic wave measurement. Adv. Space Res., 59, 11, 2691-2713. DOI: 10.1016/j.asr.2017.02.006

Smalley, R.: 2009, High-rate GPS: How high do we need to go? Seismol. Res. Lett., 80, 6, 1054-1061. DOI: $10.1785 / \mathrm{gssrl} .80 .6 .1054$

Takasu, T.: 2009, RTKLIB: Open source program package for RTK-GPS. FOSS4G 2009, Tokyo, Japan, November 2, 2009.

USGS National Earthquake Information Center: 2018, Earthquake Hazards Program.

Wang, K. and Fialko, Y.: 2015, Slip model of the 2015 Mw7.8 Gorkha (Nepal) earthquake from inversions of ALOS-2 and GPS data. Geophys. Res. Lett., 42, 18, 7452-7458. DOI: 10.1002/2015GL065201

Wang, R., Parolai, S., Ge, M., Jin, M., Walter, T.R. and Zschau, J.: 2013, The 2011 Mw9.0 Tohoku earthquake: Comparison of GPS and strong-motion data. Bull. Seism. Soc. Am., 103, 2B, 1336-1347. DOI: $10.1785 / 0120110264$

Witz, K., Hinkle, D.E., Wiersma, W., and Jurs, S.G.: 1990, Applied statistics for the behavioral sciences. Journal of Educational Statistics, 15, No. 1, 84 pp. DOI: $10.2307 / 1164825$

Xu, C., Gong, Z. and Niu, J.: 2016, Recent developments in seismological geodesy. Geodesy and Geodynamics, 7, 3, 157-164. DOI: 10.1016/j.geog.2016.04.009

Xu, P., Shi, C., Fang, R., Liu, J., Niu, X., Zhang, Q. and Yanagidani, T.: 2013, High-rate precise point positioning (PPP) to measure seismic wave motions: An experimental comparison of GPS PPP with inertial measurement units. J. Geodesy, 87, 4, 361-372. DOI: $10.1007 / \mathrm{s} 00190-012-0606-\mathrm{Z}$

Yu, W., Ding, X., Chen, W., Dai, W., Yi, Z. and Zhang, B.: 2018, Precise point positioning with mixed use of time-differenced and undifferenced carrier phase from multiple GNSS. J. Geodesy, 1-10. DOI: $10.1007 / \mathrm{s} 00190-018-1201-8$

Zheng, Y., Li, J., Xie, Z. and Ritzwoller, M.H.: 2012, 5Hz GPS seismology of the El Mayor-Cucapah earthquake: Estimating the earthquake focal mechanism. Geophys. J. Int., 190, 3, 1723-1732. DOI: $10.1111 /$ j.1365-246X.2012.05576.x

Zumberge, J.F., Heflin, M.B., Jefferson, D.C., Watkins, M.M. and Webb, F.H.: 1997, Precise point positioning for the efficient and robust analysis of GPS data from large networks. J. Geophys. Res. Solid Earth, 102, B3, 5005-5017. DOI: 10.1029/96JB03860 